\title{
Enhancement of Vertebrate Cardiogenesis by a Lectin from Perivitelline Fluid of Horseshoe Crab Embryo
}

Surendra Ghaskadbi ${ }^{1}$, Vidya Patwardhan ${ }^{1}$, Manideepa Chakraborthy ${ }^{2}$, Swati Agrawal $^{1}$, Mahesh Kumar Verma $^{2}$, Anil Chatterjee ${ }^{3}$, Nibedita Lenka ${ }^{2}$ and Pradeep B. Parab ${ }^{2}$

${ }^{1}$ Agharkar Research Institute, G.G. Agarkar Road, Pune 411 004, India

${ }^{2}$ National Center for Cell Science, NCCS Complex, Pune 411007 , India

${ }^{3}$ National Institute of Oceanography, Dona Paula, Goa 403 004, India

\section{Running title: Crab lectin enhances vertebrate cardiogenesis}

Correspondence: Surendra Ghaskadbi, Ph.D.

Agharkar Research Institute, G.G. Agarkar Road

Pune 411 004, India

E-mail: ghaskadbi@gmail.com

Telephone No. 91-20-25654357, 25653680

Fax No. 91-20-25651542

\begin{abstract}
Cardiac myocytes are the first cells to differentiate during the development of a vertebrate embryo. A wide variety of molecules take part in various steps in this process. While exploring biologically active molecules from marine sources, we found that a constituent of perivitelline fluid from embryos of the Indian horseshoe crab can enhance growth and differentiation of chick embryonic heart. We have purified the factor and identified the cardiac promoting molecule to be a novel lectin. We show that this molecule influences cardiac development by increasing the number of cells constituting the heart and by modulating the expression of several cardiac development regulatory genes in chick embryos. Using mouse embryonic stem cells we show that the cardiac myocyte enhancing capacity of this molecule extends to mammals and its effects can be blocked using methylated sugars. This molecule may prove to be an important tool in the study of cardiomyocyte differentiation.
\end{abstract}

\section{Key words}

Vertebrate heart development, Lectin, Enhancement of differentiation, Chick embryo, mouse ES cells, perivitelline fluid, horseshoe crab embryo 


\section{Introduction}

During vertebrate embryonic development, heart formation involves a series of tightly regulated molecular and morphogenetic steps, with complex interactions between different cell types and regulatory molecules, including extracellular matrix components, and growth and transcription factors. In early chick embryo, cells destined to contribute to heart are localized to posterior epiblast [1]. Prior to gastrulation, these cells migrate rostrally to occupy position in the primitive streak just caudal to Hensen's node around Hamburger Hamilton $(\mathrm{HH})$ stage 3 [2] and by HH stage 4, pass through the primitive streak into mesoderm, migrate anteriolaterally to form the bilateral anterior lateral plate mesoderm [3]. Specification of these cells to cardiac lineages begins while the cells are still in the primitive streak [4] and continues through late gastrulation as the cells reach anterior lateral plate [5] to form bilateral heart forming regions (HFRs). Soon after their specification, cardiac precursors converge along the ventral midline of the embryo to form a linear, beating heart tube. Differentiation of cardiac myocytes is concomitant with organogenesis of the heart [6].

Endoderm of the anterior lateral plate secretes signaling molecules like insulin, insulin-like growth factor II, activin and fibroblast growth factors [7]. These molecules promote survival of specified premyocardial cells as well as differentiating myocytes. Bone Morphogenetic Proteins (BMPs) play an inductive role [8], while BMP antagonists like noggin and chordin block cardiogenesis $[6,9]$. BMP2, in combination with FGF2, is able to induce the expression of definitive cardiogenic markers in non cardiogenic mesodermal cells [10].

In response to the cardiogenic signals, competent mesodermal cells destined to cardiomyocyte lineage express homeobox gene $N k x 2.5$, an early marker for cardiomyocyte differentiation [11]. $\mathrm{Nkx} 2.5$ cooperates with zinc finger transcription factor of the GATA family to activate cardiac gene expression [12]. GATA factors play an essential role in cardiac tube formation [13]. Expression of structural proteins like myosin marks the terminal differentiation of the precursors into mature, functional myocytes. Mature cardiac myocytes express either ventricular- or atrialspecific myosin molecules depending on their diversification fate either to ventricular or atrial lineage. 
The embryonic extracellular matrix, which is comprised of glycosaminoglycans, glycoproteins, collagens, and proteoglycans, is believed to play multiple roles during heart morphogenesis [14]. An anterior-posterior concentration gradient of fibronectin on the endodermal surface of the mesoderm-endoderm interface in early chick embryo has been implicated in the rostral migration of precardiac mesoderm cells $[15,16]$. At $\mathrm{HH}$ stage 5, during directional movement, the precardiac cells use the fibronectin gradient in a haptotactic manner to actively migrate across the substratum [15]. Further, during heart compartmentalization, adhesion molecules such as cadherins and fibronectins and associated intracellular signaling pathways coordinate morphogenesis [16].

In the present report, we have used chick embryo explants cultured in vitro and mammalian murine embryonic stem (ES) cells to understand cardiogenesis during early development. We have shown that, in chick embryo a component of perivitelline fluid (PVF) from the embryo of an Indian horseshoe crab, Tachypleus gigas Müller, a marine arthropod, influences cardiac development in a dramatic manner by enhancing the size of the heart while the rest of the embryo is barely affected. When cultured gastrulating chick embryos were allowed to grow in presence of appropriate amount of PVF of horseshoe crab embryos of stage 19, we found a significantly larger heart in treated embryos. The cardiac development enhancing activity of PVF resided with a lectin with a relative molecular mass of $2.7 \times 10^{4}$, made of 221 amino acid residues, which was found to be identical to that of Limulus lectin L6 of Japanese horseshoe crab Tachypleus tridentatus [17]. Moreover, the enlargement of heart was found to be due to an increase in the cell number that constituted the heart and was not a hypertrophic response. In fact, several of the cardiac regulatory molecules were also modulated by this molecule. Here we report, for the first time, a factor that enhances exclusively the cardiac development.

In order to find whether the remarkable cardiac development promoting activity of this lectin extends to mammals too, we treated mouse embryonic stem (ES) cells with this factor during differentiation. The ES cells being pluripotent take up several independent fates including that of cardiac myocytes during differentiation [18] and the hallmark of cardiomyocytes, the rhythmic pulsating activity, distinguishes these cells among the differentiating heterogeneous cell population. When the ES cells were allowed to differentiate in presence of the lectin from PVF, the number of beating clusters was increased indicating enhancement in cardiomyogenesis. 
Taken together, these results underscore a cardiac development promoting principle from the PVF with activity extending from aves to mammals.

\section{Methods}

\section{Collection of PVF:}

Naturally fertilized Indian horseshoe crab (Tachypleus gigas Müller) stage 19 embryos [19] were collected from the Bay of Bengal at Balasore (Lat. 21 ${ }^{\circ} 27^{\prime} \mathrm{N}$, Long. $87^{\circ}$ 04' E), Orissa, India, and transferred to the laboratory. The eggs were thoroughly cleaned with chemically reconstituted sterile, chilled seawater and transferred to a sterile plastic centrifuge tube with a minute hole in its base. This was in turn placed in a sterile intact centrifuge tube. The vitelline membrane of the embryos was pierced with a needle and immediately the tube duplex was centrifuged at 5000 $\mathrm{rpm}, 10 \mathrm{~min}$. at $4^{\circ} \mathrm{C}$. The liquid in the outer tube was collected and aliquoted and stored at $-70^{\circ} \mathrm{C}$ as PVF. Protein content was estimated by UV spectroscopy and Bradford's assay [20].

Treatment of stage 4 chick embryo explants with whole PVF/ PVF Fraction VII:

Freshly laid fertile eggs of white Leghorn chicken were incubated at $37^{\circ} \mathrm{C}$ for $18 \mathrm{hr}$., so that they could develop to Hamburger Hamilton $(\mathrm{HH})$ stage 4 [2]. These embryos were cultured using New's single ring technique [21]. Embryos were treated with either PVF or Fraction VII of it at appropriate concentrations decided as described before [22]. In brief, $100 \mu 1$ of Pannet Compton (PC) saline [23] containing appropriate amount of test chemical was carefully placed inside the ring in such a way that the cultured embryo encircled by the ring is completely bathed in the test solution. Controls received equal volume of plain PC saline. After 30 minutes at room temperature for diffusion, the cultures were transferred to $37^{\circ} \mathrm{C}$ for duration ranging from 6 to 36 hours, depending on the developmental stage at which the effects were studied. At the end of the treatment period, embryos were observed under dissection microscope for overall morphological effects of the treatment and then processed as required for the planned downstream processing.

Embryos developed to $\mathrm{HH}$ stage 10 [2] at the end of 18 hours of post-culture incubation and to HH stage 14 [2] by 36 hours. By stage 10, beating heart tube is formed and bent to the right of the embryo while at stage 14 [2], extensive network of blood vessels develops and the looped heart pumps significant amount of blood through these [23]. Embryos at these stages were fixed 
in acetic alcohol and stained with hematoxylin-eosin. Morphological features and overall development of treated embryos were compared to those of controls (PC saline treated).

For histological studies, embryos after 18 hours and 36 hours of treatment were fixed in Bouin's fixative and paraffin sections of $5 \mu \mathrm{m}$ thickness were stained with hematoxylin-eosin. Serial sections mounted in DPX were studied and compared between control and treated embryos.

Gel Exclusion Fast Performance Liquid Chromatography (FPLC)

$0.5 \mathrm{ml}$ of crude PVF was subjected to gel exclusion FPLC (Amersham Pharmacia) using two 30 cm pre-packed columns of Superose 12. $10 \mathrm{mM}$ phosphate buffer (13.4 ml of $0.5 \mathrm{M} \mathrm{Na}_{2} \mathrm{HPO}_{4}$, $3.3 \mathrm{ml}$ of $1 \mathrm{M} \mathrm{NaH}_{2} \mathrm{PO}_{4}$ and $8.5 \mathrm{~g} \mathrm{NaCl}$ in $1000 \mathrm{ml}, \mathrm{pH} \mathrm{7.4)}$ was used as an eluent to collect 0.5 $\mathrm{ml}$ fractions at a flow rate of $0.5 \mathrm{ml}$ per minute for a total elute of $60 \mathrm{ml}$. AUFS and chart speed used for the chromatography were 0.1 units each.

Fractions which eluted under the same peak were pooled and concentrated using Centricon columns (Millipore, U.S.A.). Protein content was estimated by UV spectroscopy. Fraction VII was found to be the most prominent elute. $10 \mu \mathrm{g}$ protein from Fraction VII was subjected to $12.5 \%$ SDS PAGE to determine the size and heterogeneity of the constituent protein.

\section{Amino acid sequence analysis of constituent of Fraction VII:}

The single band found in Fraction VII of PVF on SDS PAGE was excised and submitted to W. M. Keck Biomedical Mass Spectrometry Laboratory of Biomolecular Research Facility, University of Virginia Health System, Charlottesville, USA for identification of the protein by amino acid sequencing.

\section{$\underline{\text { Cardiac cell count: }}$}

Entire hearts from cultured stage-matched untreated embryos and those treated with $20 \mathrm{ng}$ fraction VII for 24-32 hours were dissected out in live condition using extremely fine glass needles. These were transferred to chilled Dounce homogenizer, and homogenized using a loose piston in nucleus extraction buffer (TENM2- sucrose buffer- $10 \mathrm{mM} \mathrm{NaCl}, 1 \mathrm{mM} \mathrm{MgCl} 2,1 \mathrm{mM}$ $\mathrm{MnCl}_{2}, 15 \mathrm{mM}$ triethanolamine, $\mathrm{pH}$ 7.6, 0.3 M sucrose) to extract intact nuclei [24]. To the homogenate ethidium bromide was added ( $2 \mathrm{ng} / \mathrm{ml}$ final concentration) and incubated on ice for 
20 min. Neubauer's chamber was charged with appropriately diluted homogenate and fluorescent nuclei were counted under UV light.

Whole Mount in situ hybridization:

Chicken Brachyury [25] cDNA cloned in $p B S$ vector was a kind gift from Prof. J.C. Smith, Cambridge, U.K. The recombinant plasmid $p c B R A 9$ was linearized with XbaI and transcribed using T3 RNA polymerase in presence of DIG labeled UTP to get antisense transcript of 350 bases. Chicken noggin [26] cDNA cloned into pBS vector $(c N O G)$ was gifted by Dr. J. Cooke, London, U.K. Recombinant plasmid $p c N O G$ was linearized with SacII and transcribed using T7 RNA polymerase in presence of DIG labeled UTP to generate antisense transcript of $1.3 \mathrm{~kb}$ size. Chicken Ventricular Myosin Heavy Chainl (VMHC1) [27] cloned in pGEM 4Z was a gift from Prof. D. Bader, Tennessee, U.S.A. The recombinant plasmid pc $V M H C 1$ was linearized with NdeI and transcribed using T7 RNA polymerase in presence of DIG labeled UTP to get antisense transcript of $3 \mathrm{~kb}$ size.

For whole mount in situ hybridization, the protocol described by Nieto et al. [28] was followed for all genes except for $\mathrm{c} V M H C 1$, where protocol of Wilkinson [29] was used. Stage 4 embryos with or without treatment with $20 \mathrm{ng}$ fraction VII were incubated for 6-36 hours till they reached $\mathrm{HH}$ stage $5,7,9 / 10$ or higher, and were fixed in $4 \%$ paraformaldehyde overnight at $4{ }^{\circ} \mathrm{C}$. Subsequently these were dehydrated through the grades of PBS: methanol and stored at $100 \%$ methanol at $-20^{\circ} \mathrm{C}$ for not more than a week. Prior to hybridization, embryos were rehydrated, permeablized with $10 \mu \mathrm{g} / \mathrm{ml}$ proteinase $\mathrm{K}$, re-fixed in $4 \%$ paraformaldehyde containing $0.2 \%$ glutaraldehyde. After equilibrating in hybridization mix overnight at $-20^{\circ} \mathrm{C}$ followed by incubation at hybridization temperature for 6 hours, embryos were hybridized overnight at suitable temperature with antisense DIG labeled riboprobe. Nonspecifically bound probe was eliminated during stringency washes and using RNase treatment. Hybridized probe was detected using alkaline phosphatase tagged anti DIG antibody after blocking the non-specific protein binding sites with $10 \%$ fetal calf serum. Excess antibody was washed off and specific antigenantibody complexes were localized using BCIP-NBT colour reaction. 
Quantitative Real time RT-PCR

Stage 4 embryos were treated with 20 ng PVF Fraction VII for 6-24 hours till the comparable control embryos reached stage 5,7,9/10-12. The prospective heart forming region/ forming heart tubes/ well formed beating heart tubes, depending on the stage of harvest (Fig.3 a, b, c), were carefully dissected out. The tissue was homogenized in Trizol reagent (Sigma) and total RNA was isolated as per manufacturer's protocol. RNA was separately extracted from the rest of the embryo sans the heart/ heart forming regions. $4 \mu \mathrm{g}$ of isolated RNA was used for cDNA synthesis and $2 \mu \mathrm{l}$ of the cDNA was used for a $25 \mu \mathrm{l}$ real time gradient PCR reaction (BioRad iCycler) using 2X iQ SYBR Green Supermix (BioRad) and primers (listed below). The conditions used were as follows: Initial denaturation at $95^{\circ} \mathrm{C}$ for 5 minutes followed by 40 cycles of denaturation at $95^{\circ} \mathrm{C}$ for 1 minute, annealing for 1 minute and extension at $72^{\circ} \mathrm{C}$ for 1 minute and final extension of $72^{\circ} \mathrm{C}$ for 10 minutes. The threshold cycle $(\mathrm{Ct})$ values were recorded and the fold change calculated according to the formula: Fold change $=2^{-(\Delta(\Delta \mathrm{C}} \mathrm{T}^{))}$. The quality of the amplified DNA and the appropriate size was verified by electrophoresis of the PCR product on a $1.5 \%$ agarose gel in $0.5 \mathrm{X}$ Tris Borate EDTA.

\begin{tabular}{|c|c|c|}
\hline Gene & Primer sequence & $\begin{array}{l}\text { Annealing temperature } \\
\left({ }^{\circ} \mathrm{C}\right)\end{array}$ \\
\hline GAPDH & $\begin{array}{l}\text { F-AGGTGCTGAGTATGTTGTGG-3' } \\
\text { R- ATATCATCATACTTGGCTGGT-3' }\end{array}$ & 55 \\
\hline GATA5 & $\begin{array}{l}\text { F-CGGCTTATTCCCACGACTCC-3' } \\
\text { R-TGCTCTCAAAGTGTCCGGCC-3' }\end{array}$ & 57.6 \\
\hline$N k x 2.5$ & $\begin{array}{l}\text { F- AGACAGAGGAAGAGGAGGAA-3' } \\
\text { R- TTGCAGGCAGGGCTGTTGT-3' }\end{array}$ & 58.7 \\
\hline$A M H C 1$ & $\begin{array}{l}\text { F- CCGCACCACAGAAGACCAGAT-3' } \\
\text { R- GGAGGAGCACTTGGCATTGAC-3' }\end{array}$ & 65 \\
\hline VMHC1 & $\begin{array}{l}\text { F- TCTTATATCTGGGAGCCAGG-3' } \\
\text { R- GCTACAAACACCAAGCAGAG-3' }\end{array}$ & 61.2 \\
\hline Noggin & $\begin{array}{l}\text { F- ATCTAATCGAGCACCCGGAC-3' } \\
\text { R- GCGATGATGGGGTACAGGAT-3' }\end{array}$ & 62.3 \\
\hline
\end{tabular}


Maintenance of ES cells and differentiation into cardiomyocytes:

The murine embryonic stem cell (ESC) line D3 was maintained with or without feeder layer as described [30]. In brief, the ES cells were grown in DMEM supplemented with 15\% FBS, 1x non essential amino acids, 1x L-glutamine, 1x penicillin streptomycin (all from Invitrogen), $0.007 \%$ beta mercaptoethanol (Sigma) and $1000 \mathrm{U} / \mathrm{ml}$ of LIF (ESGRO) (Invitrogen). Cells were passaged every 48 hours by enzymatic dispersion using $0.25 \%$ trypsin EDTA (Invitrogen). We have followed the method of hanging drop culture [30] for 2 days (0-2 days) followed by 3 days in suspension culture for differentiating the ES cells into cardiomyocytes and the medium was same as that used for ES cell culture but without LIF supplementation. This resulted in the formation of three dimensional embryoid bodies (EB). The EBs were plated on day 5 on gelatin coated 48 well dishes (Corning) with single EB per well and 12 EBs were plated for each set of experiment and control. The culture medium was changed every alternate day. The cardiac differentiation of EBs was monitored at different stages of development and the number of beating EBs and beating clusters per EB were counted to assess the efficacy of differentiation.

\section{Influence of PVF on cardiomyogenesis:}

To determine the effect of PVF Fraction VII on cardiomyogenesis and to discern the effective time window of action, the medium was supplemented with $300 \mathrm{ng} / \mathrm{ml}$ of Fraction VII at different time periods (0-2 days, 2-5 days and day 5) during differentiation and cardiomyogenesis was monitored. Same amount of PBS was used in control samples. In another set of experiment we dialyzed the Fraction VII against the culture medium to nullify the effect of PBS and used it at different time periods. Additionally, various concentrations (30 ng/ ml, 300 $\mathrm{ng} / \mathrm{ml}$ and $3 \mu \mathrm{g} / \mathrm{ml}$ ) of Fraction VII were added to the medium during early stage of differentiation (0-2 days) to assess the optimum concentration required for cardiomyocyte induction. Same amount of DMEM was used in control set of experiment.

RNA isolation from EBs, reverse transcription and quantitative real time PCR:

Total RNA was harvested using Trizol (Sigma) from control and PVF Fraction 7 treated EBs at different stages of differentiation and treated with RQ1 DNase (Promega) to remove residual DNA contamination. Purified RNA ( $3 \mu \mathrm{g})$ was used for first strand cDNA synthesis using 
MMLV reverse transcriptase (RT, Promega) following the manufacturer's recommendations. Real time PCR was performed using SYBR green (Bio-Rad) chemistry. The PCR was performed in an optical thermal cycler (Bio-Rad) and the data were normalized with $\beta$-actin. The data are presented as mean $\pm \mathrm{SEM}$ (standard error of mean) using three replicates. The t-test was performed to measure the significance ( $\mathrm{P}$ value) among the groups. ${ }^{*} \mathrm{P}<0.05 ; * * \mathrm{P}<0.01$.

\begin{tabular}{|l|l|c|}
\hline \multicolumn{1}{|c|}{ Name } & \multicolumn{1}{|c|}{ Primer sequences } & $\begin{array}{c}\text { Annealing temperature } \\
\left({ }^{\mathbf{0}} \mathbf{C}\right)\end{array}$ \\
\hline$\beta$-Actin & $\begin{array}{l}\text { F-AGCCTTCCTTCTTGGGTATGG-3' } \\
\text { R-ACCGATCCACACAGAGTACTTGC-3' }\end{array}$ & 58 \\
\hline Brachyury & $\begin{array}{l}\text { F-CCTATGCGGACAATTCATCT-3 } \\
\text { R-TACCATTGCTCACAGACCAGA-3 }\end{array}$ & 56 \\
\hline$\alpha M H C$ & $\begin{array}{l}\text { F-GTGAGCGGCGCATCAAGG-3' } \\
\text { R-GCTGGAGAGGTTATTCCTCG-3 }\end{array}$ & 56 \\
\hline$\beta$ MHC & $\begin{array}{l}\text { F-ACCAACCTGTCCAAGTTC-3' } \\
\text { R-GGCTCCAGGTCTGAGGG-3' }\end{array}$ & 56 \\
\hline Noggin & $\begin{array}{l}\text { F-GGCGGCCAGCACTATCT-3' } \\
\text { R-GACCACAGCCACATCTGT-3' }\end{array}$ \\
\hline Chordin & $\begin{array}{l}\text { F-TGGAGACCAAGCCTCAGC-3' } \\
\text { R-TCTGAGCCATAGAATCCC-3' }\end{array}$ \\
\hline
\end{tabular}

PVF fraction VII- sugar competition experiment:

To determine whether the mechanism of action of PVF fraction VII could be competed by sugars, galactose and mannose were used for its binding. Glucose was used as a sugar control. The $0.9 \%(\mathrm{w} / \mathrm{v})$ solution of sugar (glucose, galactose or mannose) was used at a dilution of 1:10 with complete medium. Thus, the final concentration of galactose and mannose was $0.09 \%$ while the final concentration of glucose remained high because glucose was already present $(4.5 \mathrm{~g} / \mathrm{L})$ in the complete medium. The sugars and PVF fraction VII $(300 \mathrm{ng} / \mathrm{ml})$ were mixed in the medium and incubated for 15 minutes at room temperature and then added to the cells during differentiation. In another set of experiment methyl alpha galactose and methyl alpha mannose were used at the same concentration $(0.09 \%$ final). The methylated sugars are believed to have 
higher affinity for lectins than normal sugars. All the treatments with sugar were done at 0-2 days of differentiation. Cardiac differentiation and beating cluster counting were done as above on day 10 of differentiation.

\section{Results}

Promotion of heart development in chick embryo by whole PVF:

Gastrulating chick embryos treated with $30 \mu \mathrm{g}$ of whole PVF caused enlargement of heart in $83 \%$ of the developing chick embryos after 18 hours of incubation. In these embryos brain development, axis elongation and somite number were comparable to those of controls. PVF at $3 \mu \mathrm{g}$ concentration also caused enlargement of embryonic heart but was less effective (57\% of the embryos with enlarged heart; Table 1).

Fractionation of PVF, and characterization and identification of Fraction VII:

On Gel Exclusion FPLC, PVF was separated into 7 distinct fractions (Fig. 1A) of which, Fraction VII (PVF Fraction VII) had the maximum amount of protein $(3 \mu \mathrm{g} / \mu \mathrm{l})$. When subjected to $12.5 \%$ SDS PAGE under reducing condition, it revealed a single species of protein of about 27 kD size (Fig. 1B). We have used PVF Fraction VII for subsequent experiments. The amino acid sequencing analysis of purified PVF fraction VII revealed it to have the following 221 amino acid residues.

VQWHQIPGKLMHITATPHFLWGVNSNQQIYLCRQPCYDGQWTQISGSLKQVDADDHEV WGVNRNDDIYKRPVDGSGSWVRVSGKLKHVSASGYGYIWGVNSNDQIYKCPKPCNGA WTQVNGRLKQIDGGQSMVYGVNSANAIYRRPVDGSGSWQQISGSLKHITGSGLSEVFG VNSNDQIYRCTKPCSGQWSLIDGRLKQCDATGNTIVGVNSVDNIYRSG

Homology search on this sequence using BLAST showed it to be $100 \%$ identical to Limulus lectin L6, a lipopolysaccharide binding antibacterial protein from Japanese horseshoe crab Tachypleus tridentatus [17]. 
Promotion of heart development, angiogenesis and hematopoiesis by Fraction VII in gastrulating chick embryo:

PVF Fraction VII was found to harbour the cardiac enhancing capacity. At 200 ng concentration, about $90 \%$ of the embryos showed significantly larger heart but a little more than $50 \%$ of the embryos showed retarded brain development (Fig. 1C, D; Table 2). However, at 20 ng of Fraction VII, more than $80 \%$ treated embryos showed significantly larger heart while a small proportion of embryos (less than 15\%) showed very long and more convoluted heart tube (Table 2). Interestingly, the enlarged heart resulting from treatment appeared to be functioning normally. To study the arrangement and structures of chambers in these hearts, a set of treated embryos were serially sectioned and stained (Fig. 1E-R). These studies revealed that in treated embryos there was a significant enhancement of cardiac chamber space while the wall thickness of the heart was comparable to that of controls (Fig. 1E-R). Other tissues like brain, neural tube, notochord and somites remained largely unaffected.

When a few (22) embryos were allowed to develop for further 36 hours undisturbed after treatment with 20 ng PVF Fraction VII, the treated embryos showed not only the dramatically enlarged heart but also apparently more extensive angiogenesis and hematopoiesis as compared to stage-matched controls. Enlarged heart of the treated embryos pumped apparently larger amount of blood through visibly more intricate and extensive network of blood vessels (Fig. 1S, T); however, the quantitative assessment of the blood flow and the amount of blood will be necessary before drawing more accurate conclusion.

\section{Enhancement of noggin expression in PVF Fraction VII treated chick embryos:}

HH stage-4 embryos treated with 20 ng PVF Fraction VII incubated at $37^{\circ} \mathrm{C}$ for either 2 or $20-24$ hours with corresponding controls were subjected to in situ hybridization using antisense riboprobe for noggin. After two hours of incubation with or without PVF Fraction VII, majority of the embryos were still at stage 4. Controls showed standard pattern of expression of noggin with Hensen's node staining the darkest followed by the cells of the primitive streak, while the area pellucida showed diffused, uniform staining (Fig. 2A). Treated embryos showed enhancement of staining for noggin in all the regions, i.e., Hensen's node, primitive streak and 
the whole of area pellucida, but the overall pattern of distribution of transcript, indicated by the relative intensity of staining, remained comparable to controls (Fig. 2B).

After 20-24 hours post culturing incubation, embryos reached stage 10 or 11 where the heart is functional. At this stage, in untreated embryos noggin was uniformly expressed in the entire beating heart at a barely detectable level, if any, while in the cells of neural tube and nascent brain, higher amount of noggin was seen (Fig. 2C, D). PVF Fraction VII treatment led to a significantly higher amount of, if not de novo, noggin expression in the entire heart (Fig. 2E, F).

\section{Alteration of $V M H C-1$ expression in PVF Fraction VII treated chick embryos:}

HH stage 4 embryos treated with 20 ng PVF Fraction VII and corresponding controls, incubated at $37^{\circ} \mathrm{C}$ for $22-36 \mathrm{hrs}$ (stage 11-13), were subjected to in situ hybridization using antisense riboprobe for $V M H C-1$. Control embryos showed normal expression of $V M H C-1$ with intense staining exclusively in the ventricular myocytes (Fig. 2G, H). The rest of the embryo was completely devoid of staining. Amongst the PVF fraction VII treated embryos, a majority showed intense staining in large ventricles while a few showed staining in the entire heart (Fig. 2I, J).

Modulation of Brachyury expression in PVF Fraction VII treated chick embryos:

Embryos treated with 20 ng PVF Fraction VII for 2 hours along with controls were used for in situ hybridization using antisense riboprobe for Brachyury. In untreated embryos, the expression was prominently seen in the primitive streak, while the rest of the area pellucida was fairly clear of staining (Fig. 2K). In treated embryos there was a clearly enhanced staining for Brachyury along the primitive streak (Fig. 2L). Additionally, quite intense staining was seen in cells in the region starting from just caudal to Hensen's node that often blurred the borders of primitive streak posterior region.

Augmentation of cell number in the larger hearts formed due to Fraction VII treatment in chick embryo:

A total of 12 control and 12 Fraction VII treated embryos were used after 24-32 hours of incubation. On an average, the heart of a control embryo was counted to have $1.13-1.975 \times 10^{4}$ 
cells, while an enlarged heart of a treated embryo consisted of $2.15-3.443 \times 10^{4}$ cells. Thus the enlarged heart of a treated embryo was made of about 175\% - 190\% more cells (Fig. 2M, N).

Enhancement of some cardiac-specific genes and noggin by Fraction VII in chick embryo:

At stage 5, among the genes studied, GATA 5 showed the maximum fold increase in its transcription (more than 55 folds) upon exposure to PVF Fraction VII followed by noggin in cells of the heart forming regions (HFRs; 42 folds), while in the rest of the embryo it was not significantly changed. Transcription of $N k x 2.5$ was upregulated by about 20 folds while transcripts for structural proteins of cardiac myocytes like $V M H C l$ and $A M H C l$ were not much altered. At Stage 7, GATA 5 expression level in treated embryos was the same as that seen in comparable controls. Increment in $N k x 2.5$ and noggin were all the more modest and surprisingly AMHCl showed the highest increment at a level of 18 folds. At stage 10, structural proteins showed maximum up-regulation at less than 20 folds, while $N k x 2.5$ was enhanced by 17 folds indicating that the jump in the expression levels of cardiac regulatory and structural genes are the maximum at this stage of development (Fig 3D, E).

Enhancement of ES cell differentiation into cardiomyocytes due to PVF Fraction VII exposure in a concentration-dependent manner:

When PVF Fraction VII was added during differentiation, the number of beating clusters per EB $(4.92 \pm 0.48$ clusters per EB) increased (Fig. 3F, H, I) within 5 days of treatment as compared to the control $(2.93 \pm 0.34$ clusters per EB), while the proportion of EBs beating in control $(89.3 \pm$ $4.8 \%)$ and the treated $(95.2 \pm 4.8 \%)$ set remained nearly identical because in the control set itself almost all the EBs showed pulsating activity (3G). This enhancement was most significant when the treatment was at early time point during differentiation (0-2 days Fraction VII: $5.2 \pm$ 0.7; control: $2.97 \pm 0.4$; Fig. $3 \mathrm{~F}$ ), whereas the control and treated showed comparable results when PVF Fraction VII was added at later stages (up to 5 days; Fig. 3H). Interestingly, at the intermediate time period (2-5 days) there was slight attenuation in the cardiomyogenesis upon exposure to PVF fraction VII.

To assess the optimum concentration of PVF Fraction VII to get maximum enhancement of cardiomyogenesis, PVF Fraction VII at three different concentrations (30 ng, $300 \mathrm{ng}$ and $3 \mu \mathrm{g}$ / 
ml) was used at early stages of differentiation (0-2 days). The EBs were observed at day 5+5. The number of beating EBs as well as beating clusters per EB was counted. Among the concentrations studied, the PVF Fraction VII at $300 \mathrm{ng} / \mathrm{ml}$ PVF Fraction VII was found to be optimal (5.23 \pm 0.7 beating clusters/ EB, Fig. 3I) and it not only expedited the cardiomyogenic onset but also promoted the differentiation to a significant extent (Fig. 3I). Higher concentration ( $3 \mu \mathrm{g} / \mathrm{ml}$ with $2.97 \pm 0.28$ beating clusters/ EB) or longer exposures (data not shown) did not aid cardiac differentiation.

Effect of PVF Fraction VII on some development-specific gene expression in embryoid bodies:

Since the PVF Fraction VII had a cardiogenic activity and it could enhance cardiac differentiation in a time dependant manner, the expression of mesoderm and cardiac markers in response to Fraction VII was measured (Fig. 3J). Interestingly, addition of Fraction VII (0.3 $\mu \mathrm{g} / \mathrm{ml}$ ) could increase the Brachyury expression in early differentiating EBs (day 5) as determined by quantitative real time PCR (Fig 3J.). Consistent with the positive influence of Fraction VII, an increase in cardiac markers was also evident. Expression of cardiac specific alpha Myosin Heavy Chain $(\alpha M H C)$ as well as beta Myosin Heavy Chain ( $\beta M H C)$ was significantly increased (Fig. 3J). Taken together, Fraction VII expedited the process of mesoderm induction and subsequent cardiomyogenesis from the ES cells in vitro. Since Fraction VII increased the expression of noggin in chick embryos, we estimated its expression level in treated ES cells as well. As seen in Fig 3J, PVF Fraction VII addition enhanced the expression of both noggin and chordin at early stages (day 5) in differentiating EBs.

\section{Inhibition of PVF induced cardiac promotion in ES cells by sugars:}

To find out if the effect of PVF Fraction VII (a lectin) could be blocked by sugars, galactose and mannose, two most common monosaccharides besides glucose, were selected, keeping glucose as control as it is required for cardiac differentiation from ES cells in vitro and is a normal constituent of culture medium. These two sugars, compared to the glucose control, did not cause appreciable decrease in the number of beating clusters per EB (Fig. 3K). When methylated sugars viz., methyl alpha galactose, and methyl alpha mannose, known to bind lectins more efficiently, were added to the differentiating media with PVF Fraction VII, cardiac enhancing activity of PVF Fraction VII was blocked (number of beating clusters reduced to $2.93 \pm 0.23$ due 
to methyl-alpha-galactose and $2.5 \pm 0.43$ due to methyl-alpha-mannose, as compared to $4.8 \pm 0.3$ in control with PVF Fraction VII) (Fig. 3K).

\section{Discussion}

In the present study, we describe participation of a novel molecule in the cardiac morphogenesis in chick embryo. We discovered that total PVF from stage 19 horseshoe crab embryos [19] can enhance axial elongation, somite differentiation, brain compartmentalization and cardiogenesis at $30 \mu \mathrm{g}$ concentration. The most prominent of the observed effects was extremely enlarged heart.

In an attempt to identify the active principle(s) that bring about such spectacular effects, we fractionated the PVF. On FPLC, PVF was separated into 7 fractions with largest one being fraction VII harboring the highest amount of protein. It contained a lectin with molecular mass of $27 \mathrm{kD}$ and Blast analysis showed that its amino acid sequence was identical to Lectin L6 from hemocyte lysate of Japanese horseshoe crab Tachypleus tridentatus [17]. Lectin L6 binds bacterial endotoxin, lipopolysaccharide from the outer membrane of Gram negative bacteria with high affinity and act as a bacteriostatic agent to prevent infections in the crab [17].

At 20 ng concentration, PVF Fraction VII could bring about cardiac enhancement in majority of the embryos while the rest of the features like neural tube, notochord and gut from the treated embryos were comparable to controls. This clearly shows that we have been able to isolate, identify and characterize the molecule responsible for cardiac development promotion amongst a mixture of molecules in the PVF. Histological analysis showed that the enlarged heart from treated embryo enclosed a very large chamber space while the chamber walls are of normal thickness, comparable to those of untreated control embryos. This indicated that the heart enlargement was more likely to be due to cardiac hyperplasia rather than due to hypertrophy. To confirm the likelihood of cardiac hyperplasia, we compared the total number of nuclei in the untreated and treated hearts. For this, the entire hearts from the bulbus cordis to the sinoatrial region were cut, pooled, cells macerated and nuclei stained with ethidium bromide. We counted the fluorescent nuclei under UV to estimate the total number of cells per heart. Treated hearts were made of almost double the number of cells as compared to control hearts confirming that the heart enlargement was indeed because larger number of cells taking the cardiac fate and not because of larger sized cells. 
When the embryos were allowed to grow in presence of Fraction VII for longer, the enlargement of heart was even more obvious in comparison to matched control. Further, there was a significant enhancement of angiogenesis and hematopoiesis. This action of PVF Fraction VII became obvious only after the prolonged exposure.

Interestingly, not only the number of cells increased due to Fraction VII treatment, but the expression profiles of several cardiac specific regulatory as well as structural genes were also altered in both chick embryo as well as mouse ES cells as seen in real time RT PCR studies. In PVF Fraction VII-treated chick embryo GATA 5, a zinc finger transcription factor prominent in precardiac mesoderm [31] showed the maximum enhancement of expression. Precise role of GATA family of molecules in cardiac myogenesis is not known but studies on GATA5 null mutant embryonic mice indicate that it is probably important in early heart tube formation [32]. Its over expression early in development may be one of the causes of cardiac promotion in Fraction VII-treated chick embryos. Expression of $N k X 2.5$, a homeobox marker of the early stages of the heart field [11], was also significantly increased in the embryos due to treatment with Fraction VII. Over-expression of $N k x 2.5$ in frog and zebrafish leads to larger than normal heart in otherwise normal embryos [33]. This suggests that the propensity to become heart was controlled, at least in part, by achieving a threshold level of $N k \times 2.5$ and that raising the border zone level by external supply brought a larger number of cells to threshold [32]. This rationale might hold true for embryos treated with Fraction VII too. If the lectin in Fraction VII enhances the NKx2.5 level through a yet unknown mechanism, it could lead to the present phenotype of larger heart in an otherwise normal embryo. Maximum enhancement of GATA 5 and Nkx2.5 might be because these families of genes cooperate with each other to activate cardiac gene expression [12] and also regulate each other's expression through mutually reinforcing positive feedback loops [34]. One of the most intriguing observations of this study is enhancement of noggin transcription selectively in the heart forming region due to Fraction VII treatment in both intact embryo as well as ES cells. Classically Noggin is known to promote neural fate by inhibiting BMP signaling $[35,36]$. Similarly, the expression of Chordin, another inhibitor of BMP was also significantly enhanced in treated mouse ES cells. A study by Yuasa et al. [37] using embryonic stem cells and in mouse embryo had shown that transient inhibition of BMP signaling by Noggin induces cardiomyocyte differentiation. Our results with a phenomenal upsurge of noggin expression (more than 40 folds in chick embryo) specifically in the HFR 
within a few hours of treatment with Fraction VII at stage 4 followed by almost normal levels during subsequent development (about 4 folds at stage 7 and 10) may be reflecting this phenomenon and this surge of noggin expression might be another, possibly primary, cause of cardiac enhancement. Slightly elevated expression of noggin seems to continue even in fully functional heart at stage 10-11 of the treated embryos as seen in in situ hybridization. Similarly, an enhancement in the expression of two inhibitors of BMP, noggin and chordin was noted in mouse ES cells. This hinted at the possibility of Fraction VII mediated suppression in BMP signaling during early differentiation might be facilitating mesoderm induction and subsequent cardiomyogenesis in both chick embryo and mouse ES cells. Overall enhancement of Brachyury expression, a marker for mesodermal cells [38], might be because of more number of cells taking the cardiac mesodermal fate. Higher amounts transcripts of cardiac-specific myosin heavy chain that encode structural proteins and are markers for cardiac myocyte differentiation, were obviously because larger numbers of cells were recruited to the cardiac lineage.

We visualize the events after treatment with PVF Fraction VII in the following manner. It seems probable that treatment of embryos somehow leads to stimulation of noggin expression significantly in the HFR. This, in turn, leads to extended cardiac differentiation [37] as seen from increased GATA and $N k \times 2.5$ expression. The end result of these events is a larger heart tissue as seen from the significantly higher number of total cells making up the heart as well as increased expression of $V M H C l$ and $A M H C l$. If these really are the events that occur in the chick embryo, the same should work in mouse ES cells as an experimentally created short burst of noggin expression leads to cardiac differentiation in that system [37]. Indeed that is what we found when we examined the effects of PVF Fraction VII on noggin (and chordin) expression and the subsequent cardiomyocyte differentiation in mouse ES cells. Transient inhibition of BMP signaling by its inhibitors appears to be a crucial step in this phenomenon.

Enhanced recruitment of mouse embryonic stem cells into beating myocyte clusters due to treatment with PVF Fraction VII demonstrated that cardiac enhancing effect of this molecule was not confined to chick but extended to mammalian cells as well. Fraction VII induces cardiomyogenesis in ES cells in vitro and the effect was more specific and pronounced upon exposure of cells to Fraction VII during the onset of differentiation compared to that at later stages indicating a sensitive period for its cardiac enhancing potential. Blocking of cardiogenic 
capacity of Fraction VII with methylated sugars, which have higher affinity for lectins, indicated that the sugar/ glycoprotein binding feature of this lectin was indeed involved in cardiac promotion. Modulation of expression of a whole range of genes starting from the basic mesodermal marker like Brachyury to the terminal differentiation markers like myosins indicates that this molecule might be intervening at the very beginning of the pathway leading to the formation of cardiac myocytes, probably at the time when the cells are specified to cardiac lineage.

We strongly believe that this molecule will prove to be an important tool in the study of cardiomyocyte differentiation and plan to further elucidate the molecular mechanism of its action.

\section{ACKNOWLEDGEMENTS}

This work was supported by Department of Biotechnology, Government of India. We thank Dr. G.C. Mishra, Director, National Centre for Cell Science, Pune for discussions and suggestions. 


\section{References}

1 Hatada, Y. and Stern, C. D. (1994). A fate map of the epiblast of the early chick embryo. Development 120, 2879-2889.

2 Hamburger, V. and Hamilton, H. L. (1951). A series of normal stages in the development of the chick embryo. J. Morphol. 88, 49-92.

3. Garcia-Martinez, V. and Schoenwolf, G. C. (1993) Primitive-streak origin of the cardiovascular system in avian embryos. Dev. Biol. 159, 706-719.

4. Yatskievych, T. A., Ladd, A. N. and Antin, P. B. (1997) Induction of cardiac myogenesis in avian pregastrula epiblast: the role of the hypoblast and activin. Development 124, 25612570 .

5. Montgomery, M. O., Litvin, J., Gonzalez- Sanchez, A. and Bader D. (1994) Staging of commitment and differentiation of avian cardiac myocytes. Dev. Biol. 164, 63-71.

6 Ladd, A. N., Yatskievych, T. A. and Antin P. B. (1998) Regulation of avian cardiac myogenesis by activin/ TGFFi and bone morphogenetic proteins. Dev. Biol. 204, 407-419.

7 Sugi, Y. and Lough, J. (1995) Activin-A and FGF-2 mimic the inductive effects of anterior endoderm on terminal cardiac myogenesis in vitro. Dev. Biol. 168, 567-574.

8 Schultheiss, T. M., Burch, J. B. E. and Lassar, A. B. (1997) A role for bone morphogenetic proteins in the induction of cardiac myogenesis. Genes Dev. 11, 451-462.

9 Streit, A, Lee, K. J., Woo, I., Roberts, C., Jessell, T. M. and Stern, C. D. (1998) Chordin regulates primitive streak development and the stability of induced neural cells, but is not sufficient for neural induction in the chick embryo. Development 125, 507-519.

10 Lough, J., Barron, M., Brogley, M., Sugi, Y. Bolender, D. L. and Zhu, X. (1996) Combined BMP-2 and FGF-4, but neither factor alone, induces cardiogenesis in non-precardiac embryonic mesoderm. Dev. Biol. 178, 198-202.

11 Harvey, R. P. (1996) NK-2 homeobox genes and heart development. Dev. Biol. 178, 203-216.

12 Durocher, D., Charron, F., Warren, R., Schwartz, R. J. and Nemer, M. (1997). The cardiac transcription factors Nkx2-5 and GATA-4 are mutual cofactors. EMBO J. 16, 5687-5696.

13 Laverriere, A. C., Macneill, C., Muller, C., Poelmann, R. E., Burch, J. B. and Evans, T. (1994) GATA-4/5/6, a subfamily of three transcription factors transcribed in developing heart and gut. J. Biol. Chem. 269, 23177-23184.

14 Little, C. D. and Rongish, B. J. (1995). The extracellular matrix during heart development. Cell. Mol. Life Sci. 51, 873-882. 
15 Linask, K. K. and Lash, J. W. (1986) Precardiac cell migration: Fibronectin localization at mesoderm-endoderm interface during directional movement. Dev. Biol. 114, 87-101.

16 Linask, K. K., Han, M. D., Cai, M., Brauer, P. and Manisastry, S. (2005) Cardiac Morphogenesis: MMP-2 involvement in cellular mechanisms underlying heart tube formation and looping. Dev. Dyn. 233, 739-753.

17 Saito, T., Kawabata, S., Hirata, M. and Iwanaga, S. (1995) A novel type of limulus lectin-L6. Purification, primary structure and antibacterial activity. J. Biol. Chem. 270, 14493-14499.

18 Moretti, A. Caron, L., Nakano, A., Lam, J. T., Bernshausen A., Chen, Y., Qyang, Y. Bu, L., Sasaki, M., Martin -Puig, S., Sun, Y., Evans, S. M., Laugwitz, K. L. and Chien, K. R. (2006) Multipotent embryonic isl1+ progenitor cells lead to cardiac, smooth muscle, and endothelial cell diversification. Cell 127, 1151-1165.

19 Chatterjee, A. (1994) In: The Indian Horseshoe Crab - A Living Fossil. A Project Swarajya Publication, Cuttack, India

20 Bradford, M. (1976) A rapid and sensitive method for the quantitation of microgram quantities of protein utilizing the principle of dye-binding. Anal. Biochem. 72, 248-254.

21 New, D. A. T. (1955) A new technique for the cultivation of chick embryo in vitro. J. Embryol. Exp. Morphol. 3, 326-331.

22 Ghaskadbi, S., Elias, B., Patwardhan, V., Garde, S. Sheth, A.R. and Ghate, H. V. (1994) Mesoderm enhancing effect of human seminal plasma inhibin and its synthetic C-terminal nonapeptide fragment in the chick embryo. Indian J. Exp. Biol. 32, 450-457.

23 New, D. A. T. (1966) The culture of vertebrate embryos. Logos Press, London.

24 Ghatpande, S. K., Guttikar, G. S., Paranjape, S. G., Mulherkar, L. and Modak, S. P. (1990) Cell population growth in chick blastoderms cultured in vitro. Indian J. Exp. Biol. 28, 526530.

25 Smith, J. C., Price, B. M., Green, J. B., Weigel, D. and Herrmann, B. G. (1991) Expression of a Xenopus homolog of Brachyury $(T)$ is an immediate early response to mesoderm induction. Cell 67, 79-87.

26 Connolly, D. J, Patel, K. and Cooke, J. (1997) Chick noggin is expressed in the organizer and neural plate during axial development, but offers no evidence of involvement in primary axis formation. Int. J. Dev. Biol. 41, 389-396.

27 Bisaha, J. G. and Bader, D. (1991) Identification and characterization of a ventricularspecific avian myosin heavy chain, VMHC1: Expression in differentiating cardiac and skeletal muscle. Dev. Biol. 148, 355-364.

28 Nieto, M. A., Patel, K. and Wilkinson, D. G. (1996) In situ hybridization analysis of chick embryos in whole mount and tissue sections. Meth. Cell Biol. 51, 219-235. 
29 Wilkinson, D. G. (1992) Whole mount in situ hybridization of vertebrate embryos. In: In situ Hybridization- A practical Approach, pp. 75-83, Wilkinson D.G. (ed.) IRL Press, New York.

30 Lenka, N. (2006) Derivation and characterization of neural cells from embryonic stem cells using nestin enhancer. Methods Mol. Biol. 330, 33-54.

31 Rieter, J. F., Alexander, J., Rodaway, A. Yelon, D., Patient, R., Holder, N. and Stainier, D. Y. R. (1999) GATA 5 is required for the development of the heart and endoderm in zebrafish. Genes Dev. 13, 2983-2995.

32 Fishman, M. C. and Chien, K. R. (1997) Fashioning the vertebrate heart: earliest embryonic decisions. Development, 124, 2099-2117.

33 Cleaver, O. B., Patterson, K. D. and Krieg, P. A. (1996) Over expression of the tinmanrelated genes $X N k x-2.5$ and $X N k x-2.3$ in Xenopus embryos results in myocardial hyperplasia. Development 122, 3549-3556.

34 Schwartz, R. J. and Olson, E. N. (1999) Building the heart piece by piece: modularity of ciselements regulating Nkx2-5 transcription. Development 126, 4187-4192.

35 Re'em-Kalma, Y., Lamb, T. and Frank, D. (1995) Competition between noggin and bone morphogenetic protein 4 activities may regulate dorsalization during Xenopus development. Proc. Natl. Acad. Sci., USA 92, 12141-12145.

36 Zimmerman, L. B., De Jesus-Escobar, J. M. and Harland, R. M. (1996) The Spemann organizer signal noggin binds and inactivates bone morphogenetic protein 4. Cell 86, 599606.

37 Yuasa, S., Itabashi, Y., Koshimizu, U., Tanaka, T., Sugimura, K., Kinoshita, M., Hattori, F., Fukami, S., Shimazaki, T., Okano, H., Ogawa, S. and Fukuda, K. (2005) Transient inhibition of BMP signaling by Noggin induces cardiomyocyte differentiation of mouse embryonic stem cells. Nature Biotech. 23, 607-611.

38 Smith, J. C. (2001) Making mesoderm- upstream and downstream of Xbra. Int. J. Dev. Biol. $45,219-224$. 


\section{Legends for the figures}

Figure.1 Purification and effects of PVF Fraction VII on cultured chick embryo explants (A) FPLC profile of whole PVF. (B) On SDS PAGE, the seventh fraction (Fraction VII) showed a single band of $27 \mathrm{kD}$ size (track marked 7). When $\mathrm{HH}$ stage 4 chick embryos were grown in presence of 20 ng PVF Fraction VII for about 24 hours (D), majority had significantly enlarged hearts as compared to control embryos (C). In the histological studies, serially sectioned treated embryo (L- R) clearly showed extremely large heart as compared to normal heart of a control embryo (E-K). Note comparable thickness of heart wall in controls and treated embryos. Cardiac development enhancing effect of PVF Fraction VII was much more obvious after about 50-54 hours of incubation (T) when compared to controls (S). FB: forebrain, HB: hindbrain, Hrt: Heart; MB: midbrain, NT: neural tube

Figure 2 Molecular mechanism of action of PVF Fraction VII. On whole mount in situ hybridization, HH stage 4 embryo treated with $20 \mathrm{ng}$ of PVF for 2 hours showed enhanced expression of noggin (B) as compared to untreated control embryo (A). After about 24 hours of treatment, noggin expression could be faintly but clearly seen only in the heart of a treated embryo (E, F), while the heart of the control embryo (C, D) was almost completely devoid of noggin expression. Similarly, $20 \mathrm{ng}$ PVF Fraction VII treated embryos showed enhanced expression of $V M H C 1$. After 24 hours of treatment, in the resultant enlarged heart, larger area expressed $\operatorname{VMHCl}(\mathrm{I}, \mathrm{J})$ as compared to the normal pattern $(\mathrm{G}, \mathrm{H})$. Normal expression pattern of pan mesodermal marker Brachyury was localized to the primitive streak in controls (K) while this was more intense and extended to the cells surrounding the posterior primitive streak after 2 hours of treatment with 20 ng PVF Fraction VII (L). When the total numbers of cells making up the entire heart (M - shown in red) of control and treated embryos were compared, it was obvious that the PVF Fraction VII treatment caused almost doubling of cell number in the heart $(\mathrm{N})$. HN: Hensen's node, HRT: heart, PS: primitive streak.

Figure 3 A-E: Enhancement of expression of cardiac specific marker genes due to treatment with $20 \mathrm{ng}$ of PVF Fraction VII. Embryonic regions known to contain cardiac progenitor cells according to published fate maps were excised from control (C) and treated (T) embryos at 
stages 4 (A), 5 (B) and 7 (C) and from fused cardiac tube at stage 10-12, total RNA extracted and subjected to quantitative RT PCR (D) using primers for the genes AMHC1, GATA5, Nkx2.5, noggin and VMHC1. House keeping gene GAPDH was used as loading control. When the expression profiles of some these genes were compared across different stages (E), differential modulation of cardiac specific genes by PVF Fraction VII becomes obvious.

F-K: Induction of cardiomyocyte differentiation in mouse embryonic stem cells by PVF Fraction VII and its inhibition by methylated sugars. Treatment of mouse ES cells early (0-2 days of differentiation) with Fraction VII increased the number of beating clusters of cells per embryoid body (F) after10 days of differentiation, while the proportion of EBs beating in control and the treated set remained nearly identical because in the control set itself almost all the EBs showed pulsating activity $(\mathrm{G})$. The cells were treated with Fraction VII during early time point of differentiation (0-2 days) and observed on $\mathrm{d} 5+5(\mathrm{n}=6)$. Fraction VII treatment was most effective in enhancing the frequency of beating clusters within each embryoid body $(\mathrm{H})$ early during differentiation (0-2 days), while delayed treatment was not so effective. The EBs were treated for different time points and observed after 10 days of differentiation (days $5+5 ; n=3$ ). $300 \mathrm{ng} / \mathrm{ml}$ was found to be the most effective concentration for promoting cardiomyogenesis monitored at days $5+5$ of differentiation (n=3) (I). Addition of PVF Fraction VII lead to an early upregulation of the expression of noggin and chordin (days $5+5 ; n=3$ ) (J). There was a concurrent surge in the expression of genes which regulate both mesoderm formation (Brachyury in days $5+5 ; \mathrm{n}=3$ ), and cardiac myogenesis ( $\alpha M H C$ and $\beta M H C$ in days $5+10 ; \mathrm{n}=3)$ in mouse EBs (J). The cardiogenic activity of PVF Fraction VII was partially blocked by the galactose and mannose sugars (days 5+5) $(\mathrm{K})$. These sugars did not block the endogenous cardiac differentiation when added to the medium. However, when pre-incubated with Fraction VII, there was marginal impairment $(\mathrm{P}<0.05)$ in the inductive influence of Fraction VII by mannose when compared with that of Fraction VII alone or Fraction VII with glucose. Methylated sugars were found to be more potent in inhibiting Fraction VII activity $(\mathrm{P}<0.05)$ than their normal counterparts. Both Methyl alpha galactose (CH3-a-Gal) and methyl-alpha-mannose (CH3-aMann) singly inhibited the endogenous cardiac differentiation when added to the medium. ( $\mathrm{n}=3$ 5). 
Table 1. Whole mount studies of whole PVF treated embryos

\begin{tabular}{|c|c|c|}
\hline $30 \mu \mathrm{g}$ & Control embryos (25) & Treated embryos (29) \\
\hline $\begin{array}{l}\text { No. of somites } \\
\text { (Mean } \pm \text { S.D.) }\end{array}$ & $9.4 \pm 1.63$ & $11.6 \pm 1.3$ \\
\hline Heart & $\begin{array}{l}19 \text { Normal }(76 \%) \\
1 \text { Underdeveloped }(4 \%) \\
5 \text { Not developed }(20 \%)\end{array}$ & $\begin{array}{l}24 \text { Large }(83 \%) \\
5 \text { Normal }(17 \%) \\
0 \text { Not developed } \\
\end{array}$ \\
\hline Brain & $\begin{array}{l}19 \text { Normal }(76 \%) \\
6 \text { Underdeveloped }(24 \%)\end{array}$ & $\begin{array}{l}28 \text { Normal }(97 \%) \\
1 \text { Underdeveloped }(3 \%)\end{array}$ \\
\hline $3 \mu \mathrm{g}$ & Control embryos (25) & Treated embryos (28) \\
\hline $\begin{array}{l}\text { No. of somites } \\
\text { (Mean } \pm \text { S.D.) }\end{array}$ & $9.04 \pm 1.4$ & $10.46 \pm 1.72$ \\
\hline Heart & $\begin{array}{l}20 \text { Normal }(80 \%) \\
4 \text { Medially located }(16 \%) \\
1 \text { Underdeveloped } \quad(4 \%)\end{array}$ & $\begin{array}{l}16 \text { Large heart }(57 \%) \\
7 \text { Normal }(25 \%) \\
5 \text { Underdeveloped }(18 \%)\end{array}$ \\
\hline Brain & $\begin{array}{l}20 \text { Normal }(80 \%) \\
5 \text { Underdeveloped }(20 \%)\end{array}$ & $\begin{array}{l}22 \text { Normal }(79 \%) \\
6 \text { Underdeveloped }(21 \%)\end{array}$ \\
\hline
\end{tabular}


Table 2. Morphological studies of embryos treated with PVF- Fraction VII

\begin{tabular}{|c|c|c|}
\hline 20 ng/embryo & Control embryos (53) & Treated embryos (62) \\
\hline $\begin{array}{l}\text { No. of somites } \\
\text { (Mean } \pm \text { S.D.) }\end{array}$ & $10.32 \pm 1.7$ & $10.18 \pm 2.19$ \\
\hline Heart & $\begin{array}{l}46 \text { Normal }(86.79 \%) \\
3 \text { Underdeveloped }(5.66 \%) \\
4 \text { Not developed }(7.5 \%)\end{array}$ & $\begin{array}{l}2 \text { Normal }(3.22 \%) \\
51 \text { Large heart }(82.2 \%) \\
9 \text { Convoluted }(14.5 \%)\end{array}$ \\
\hline Brain & $\begin{array}{l}42 \text { Normal }(79.2 \%) \\
8 \text { Underdeveloped }(15.1 \%)\end{array}$ & $\begin{array}{l}50 \text { Normal }(80.6 \%) \\
12 \text { Underdeveloped }(19.3 \%)\end{array}$ \\
\hline 200 ng/embryo & Control embryos (8) & Treated embryos (11) \\
\hline $\begin{array}{l}\text { No. of somites } \\
(\text { Mean } \pm \text { S.D.) }\end{array}$ & $9.875 \pm 2.16$ & $10.77 \pm 2.43$ \\
\hline Heart & $\begin{array}{l}7 \text { Normal }(87.5 \%) \\
1 \text { Underdeveloped }(12.5 \%) \\
0 \text { Large heart }\end{array}$ & $\begin{array}{l}1 \text { Normal }(9 \%) \\
10 \text { Large heart }(90.9 \%) \\
0 \text { Underdeveloped heart }\end{array}$ \\
\hline Brain & $\begin{array}{l}7 \text { Normal }(87.5 \%) \\
1 \text { Underdeveloped }(12.5 \%)\end{array}$ & $\begin{array}{l}5 \text { Normal }(45.4 \%) \\
6 \text { Underdeveloped }(54.5 \%)\end{array}$ \\
\hline
\end{tabular}



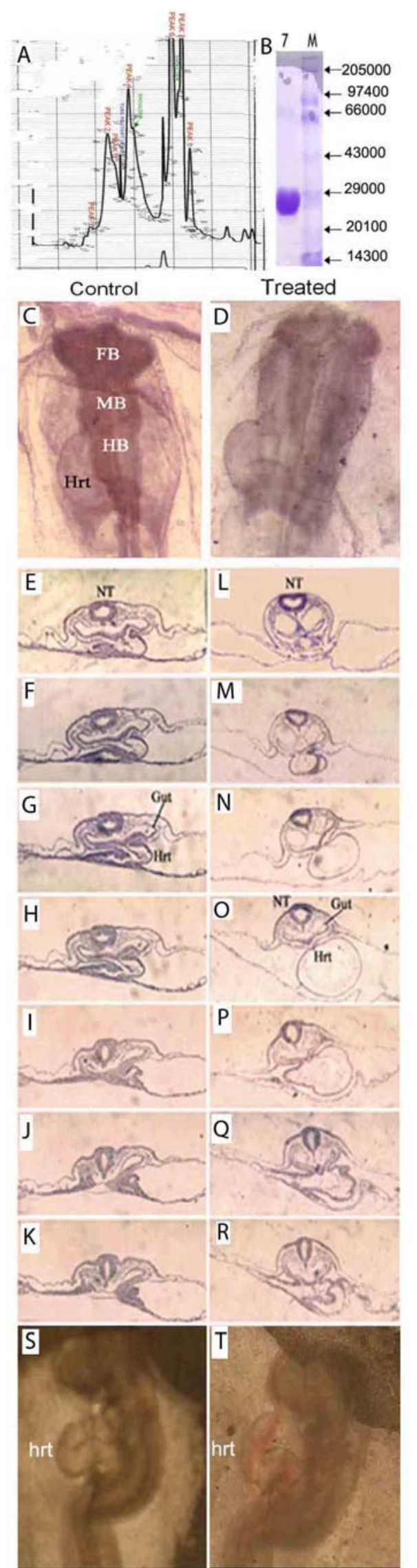

Fig.1 


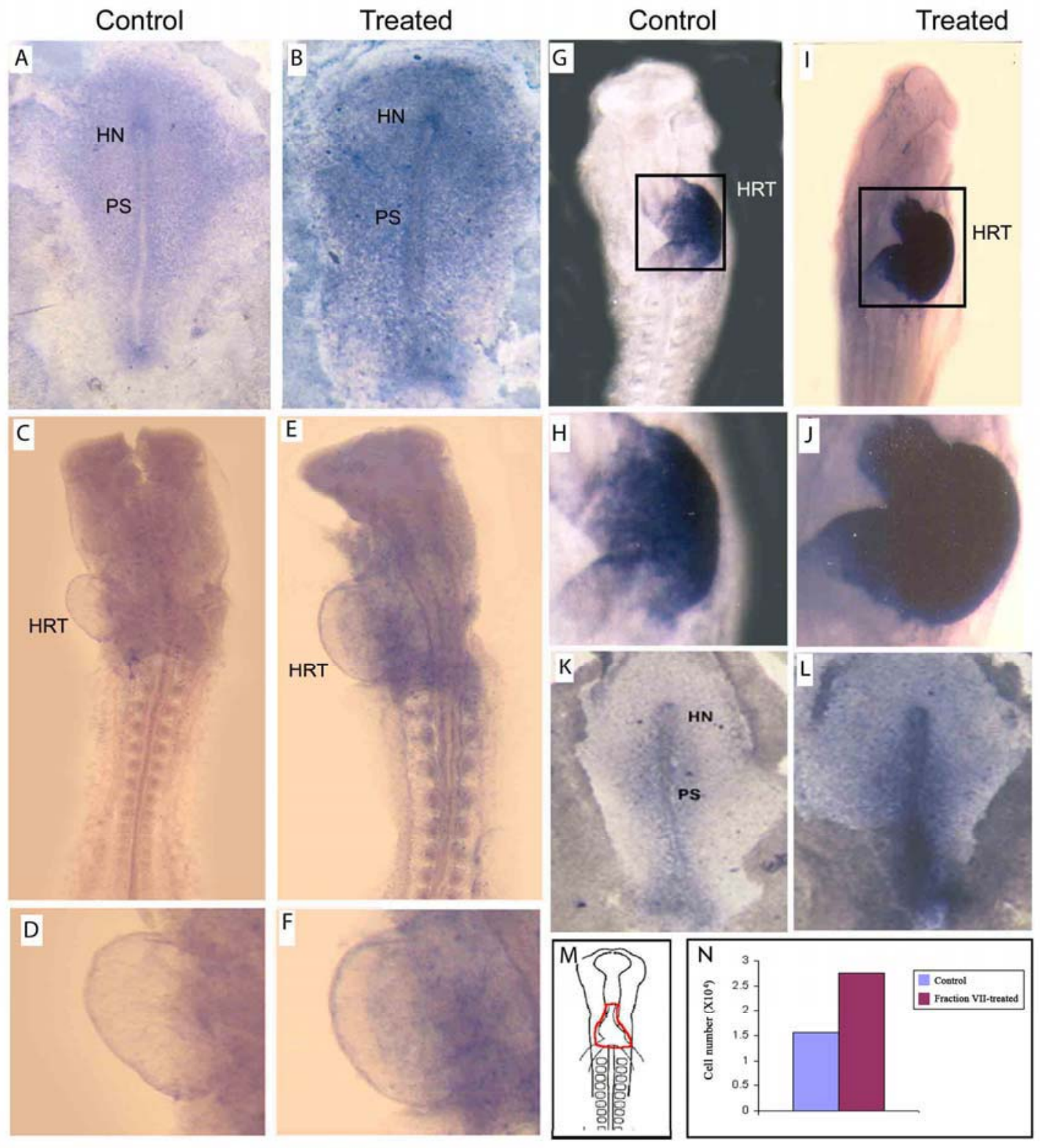

Fig.2 

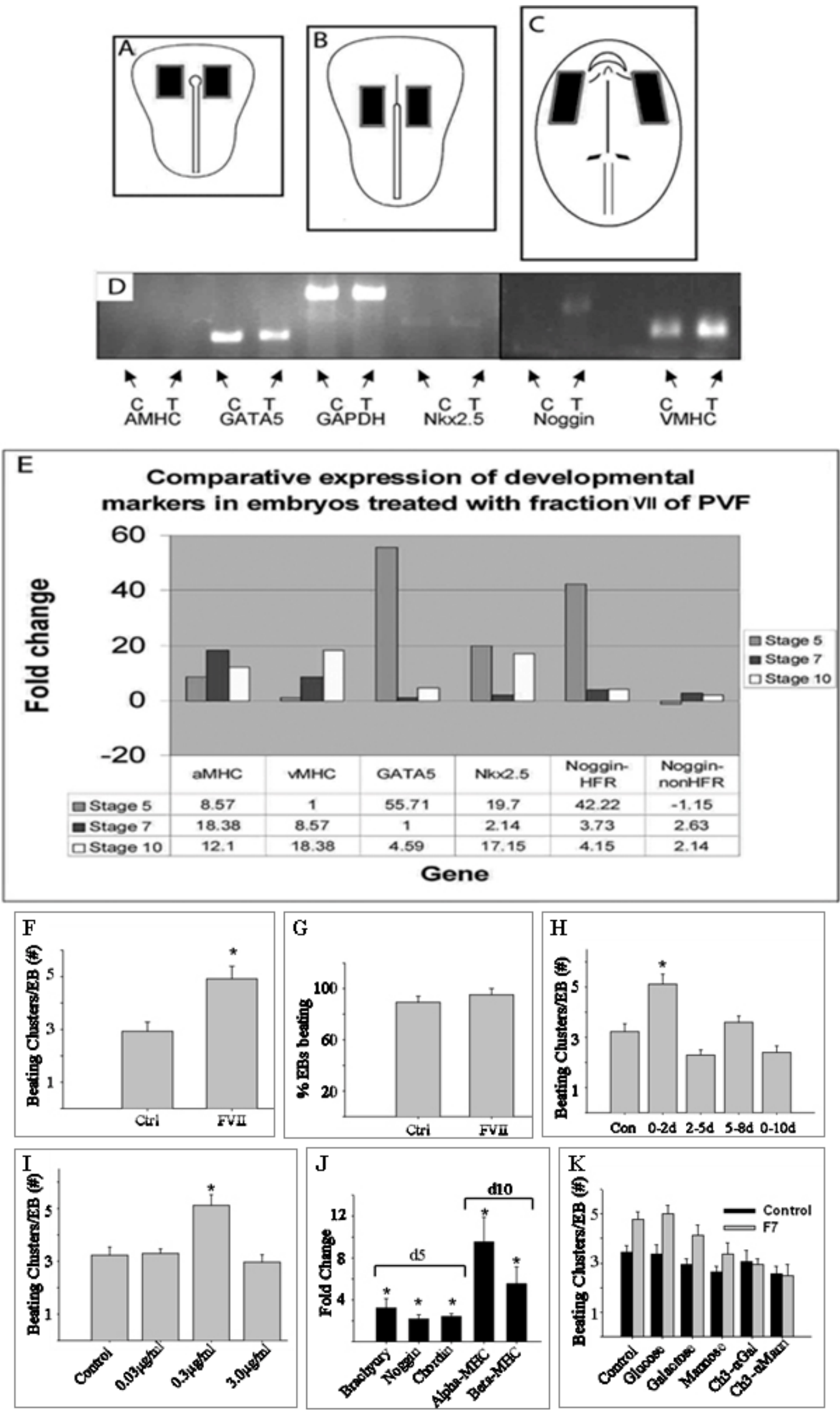

Fig. 3 